NBER WORKING PAPER SERIES

\title{
DID COMPUTER TECHNOLOGY DIFFUSE \\ QUICKLY?: BEST AND AVERAGE \\ PRACTICE IN MAINFRAME COMPUTERS, 1968-1983
}

Shane M. Greenstein

Working Paper No. 4647

\section{NATIONAL BUREAU OF ECONOMIC RESEARCH 1050 Massachusetts Avenue Cambridge, MA 02138 \\ February 1994}

This paper is a condensed version of Greenstein [1993a]. I would like to thank Ernst Berndt, Paul David, Zvi Griliches, Larry Neal, Ed Steinmueller, and Manuel Trajtenberg for useful conversations connected with this work. Seminar participants at the NBER productivity workshop, the University of Illinois, and University of Oregon provided many comments on earlier drafts. Julie Lee and Jennifer Howitt entered data, and Sandra Ospina and Ken Brown provided outstanding research assistance. Patrick McGovern and the Charles Babbage Institute deserve thanks for helping out in the assembly of the data used in this paper. The Center for Economic Policy Research at Stanford University and the Arnold O. Beckman Endowment at the University of Illinois provided funding. Only I am responsible for the errors contained in this paper. This paper is part of NBER's program in Productivity. Any opinions expressed are those of the author and not those of the National Bureau of Economic Research. 


\title{
DID COMPUTER TECHNOLOGY DIFFUSE QUICKLY?: BEST AND AVERAGE PRACTICE IN MAINFRAME COMPUTERS, 1968-1983
}

\begin{abstract}
An economy benefits from advances in technical frontiers only when new technology comes into general use. This paper measures the diffusion of computing equipment at a time when computing technology underwent dramatic technical improvement. These data shed light on the long lag between advances in computing technology and advances in economic performance of users. There is little evidence that long lags were produced by the "slow diffusion" of new technology embodied in new hardware. "Average practice" in computing advanced as rapidly as "best practice," lagging it by a maximum of 6 to 7 years.
\end{abstract}

Shane M. Greenstein Department of Economics David Kinley Hall, Box 70 University of Illinois Urbana, IL 61801 and NBER 


\section{Introcuction}

Best-practice computing technology has advanced rapidly in the last 30 years.' Yet, it is hasty to infer that economic welfare improved at the same rate. What matters for economic welfare is the advance of technologies in general use, not necessarily the advance of the best practice, which very few may put into use quickly. Despite all the attention paid to the advances in best practice, little economic research examines the diffusion of computing technology or the economic value of systems in use. ${ }^{2}$

This paper provides measures of diffusion for 1968 to 1983, a time when the best practice technology underwent rapid improvement. The analysis shows that average practice advanced rapidly in the United States. In most years, average practice advanced at a rate comparable to best practice, irrespective of the measure used for either. Average practice never lagged best practice by more than 6 to 7 years and usually by less. Compared with many other studies of the diffusion of important historical innovation of the last 200 years (e.g., Mansfield [1968]), this represents an extraordinary fast diffusion of new technology.

These results support two conclusions. First, the paper's results relate to several diffusion mechanisms, analyzed in David [1989], that could account for the long lag between advance of best practice computing technology and productivity growth. The analysis shows that there is no evidence to support the simplist possible mechanism, that hardware embodying new technology diffused slowly. This result is consistent with David's [1989] emphasis on other mochanisms, e.g., the time it takes to learn about new capabilities and the re-organize business enterprises.

\footnotetext{
I See Gordon [1989], Dulberger [1989], Cole et al [1986], Triplett [1989], Bernct, Showalter, and Woolridge [1990], Berndt and Griliches [1991], and Oliner [1993a]. Despite some disagreement, most indexes of mainframes yield advances in quality/price on the order of $20 \%$ to $25 \%$ a year over the last thirty years.

${ }^{2}$ Exceptions include: Berndt and Morrison [1991], Berndt, Morrison and Rosenblum [1992], and Bresnahan [1987].
} 
In the same spirit, the paper highlights others ways in which best practice frontiers for computing usually estimated with hedonic methods (Tripplett [1989]), may provide a deceptive indicator of the economic benefits accrueing to computer users. The basic economics of the problem is straightforward and well-known: Each old user reacts to new technology with a different adoption response. Advances in best practice do not necessarily translate into uniform economic benefits across all computer users because new practice does not uniformly replace old practice everywhere very quickly. The open issues addressed in this paper are empirical, i.e., how varied is the response across users and how does this variation influence measurement of the benefits from technical change?

\section{Data on the Installed Base of Computer Systems}

This study uses data from IDC, the best historical data available on the size of installed base of computers and their rental prices. No other comparable data source exists for the 1960s and 1970s. Only a few studies of the computing market (e.g., Micheals [1979], Phister [1979], Flamm [1987a,b], Dulberger [1989], Oliner [1993a]) have used data from a similar source and none ever exploited all facets of it. Before beginning the analysis, the paper must discuss the limitations these data impose on the measure of best and average practice. More detailed descriptions of these data are included in the appendix

The analysis begins with the December 31, 1968 report and end with the January 1, 1983 report. It begins with 1968 because this is the first year in which IDC distinguished between the number of installations within the US and outside the United States. It ends with the 1983 report, because all of IDC's census underwent a massive reclassification after 1983, the last year that IDC maintains its mainframe file separately from other types of computer systems.

This paper accepts IDCs definitions of what is a mainframe computer (as opposed to a minicomputer, a small business system or a desktop system). This makes my estimates comparable with 
Phister's [1979] and Flamm's [1987] description of the diffusion of computing equipment, which used more aggregate IDC data. ${ }^{3}$ It also makes my results comparable to Oliner's [1993a] analysis of the retirement patterns among IBM mainframes, which uses similar IDC data for IBM systems. As a secondary benefit, employing IDCs definitions removes any suspicion that the definition was chosen arbitrarily or chosen to manipulate the results (though I have found that most of this paper's analysis is robust to small changes in definitions). Over the entire 16 year period, these data concern the installed base of over 350 different computer systems. The appendix provides a list of the important included systems.

Three biases arise from maintaining exclusive use of IDCs definition of a mainframe. First, in 1968 and 1969 IDCs early definition of a mainframe is too broad, including some systems that they reclassify as "Digital Dedicated Application" in 1970.4 This will influence some of the results below. Second, more redefinition problems arise on a smaller scale when IDC began several data bases for systems other than mainframes (i.e., minicomputers, small business systems, desktop). Its researchers occasionally move a system into the mainframe category that was not there previously or move a system out of the mainframe category that was there previously. Most of these redefinitions do not matter, but a few influence the results below. The most important case is IDCs decision to include the IBM System 36 in the sample in 1976 (estimated installed base at 5000 units) and exclude it from mainframes thereafter (but include it in "small business systems"). Third, by the end of the sample, the difference between mainframes and some large mini-computers (a.ka. "super-minis") becomes blurred, raising questions about the survey's completeness. The main issue is whether IDC includes in the mainframe category all the super-minicomputer systems that were close substitutes for mainframes. A

\footnotetext{
${ }^{3}$ Phister identifies several years in which IDC revised the reported number of installations in previous years, particular for IBM models in 1967-1972. In those cases, Phister's reported updates were used.

- This occurred as part of a general reclassification of all IDC censuses.
} 
reasonable case could be made that IDC included most relevant systems. ${ }^{5}$ A reasonable case could also be made that they did not, especially by $1983 .{ }^{6}$ Overall, the omissions do not bias important results below except in one place, which will be noted

\section{A first look at different vintages.}

IDCs surveys do not record when a user installs each new acquisition. However, IDC does record the date (year-month) at which each model of a system was first installed anywhere in the United States. For example, the IBM 360/20 was first installed in November 1965, the IBM 370/125 in May 1973, and the IBM 3031 in February 1978. A summary of product introductions is presented in the appendix. Call this number VINTAGE. VINTAGE provides one measure of the technology embedded in each system, because systems developed later and introchuced later tend to be better in several respects than those developed and introduced earlier.

As a measure of technological capability, VINTAGE has two significant drawbacks. First, it does not measure differences in the performance of different systems introctuced at the same time. Thus, VINTAGE is likely to be a poor measure of success in inter-system competition. This deficiency is difficult to correct because there is no standard method for using installed base to weight results (e.g., See Greenstein [1993b] for one such attempt). A second important drawback is that VINTAGE

\footnotetext{
II is not clear whether the money spent on super-minis ever amounted to more than a small fraction of the amount of money spent on mainframes. According to the 1983 IDC census for mini-computers and mainframes, the value of installed base associated with super-minicomputers came to roughly half the value of all minicomputers, or roughly 15 percent of the value of the installed base of mainframes. IDCs census differs from the other censuses, particularly CBEMA's, because IDC includes several systerns as mainframes (i.e., those from IBM) which others classify as super-minicomputers. This matters a great deal by the end of the sample. For example, according to the CBEMA [1992], in 1976 mainframe shipments reached over 5 billion dollars, while the total spent on all minicomputers was 1.8 billion. By 1982, however, mainframe shipments reached 10.6 billion and minicomputer shipments reached 7.7 billion. CBEMA does not state what fraction went to superminicomputers.

- The most questionable omissions in IDCs mainframe tables are those regarding the VAX models from DEC, and similar competitive models from other firms such as Prime and Data General.
} 
overlooks differences between cohort and age effects. It assumes that the same measured difference between an earlier and later technical vintage means the same thing in two different periods. That is, it presumes that a 1968 technology is better than a 1965 technology by exactly the same amount that a 1981 technology is better than a 1978 technology, and so on Some corrections are possible (see below).

The advantage of using VINTAGE for measuring technical capability is that it available for all systems in all 16 years of the data and it is easy to use. Second, over the long nu, VINTAGE provides a quick and reasonable measure of improvements in new technology embedded in successive generations of computing equipment, which is fine for the diffusion issues addressed in this paper. Third, this measure does not rely on an arbitrary estimate of best practice tochnology, nor does it rely on a company's announcement regarding the product. Rather, it uses a historical event, when the product first came to market. Thus, it is an appealing definition for an economic study.

Most important, VINTAGE provides a bound on the degree of technical knowledge embodied in a system This occurs for three reasons. First, the installed base of systems in use must be younger than VINTAGE indicates because the date of first installation is older than the date at which most users install their rented or purchased model. Second, VINTAGE overstates a system's true technical age in situations where new installations of an old vintage technology are using technology retrofitted with improvements. Lastly, VINTAGE does not correct for typical utilization rates of especially older systems. In other words, it overstates how important old systems may be by assuming a "one-hossshay" model for old systems - if a system is installed, then it is still in use. In sum, VINTAGE will give the most pessimistic picture possible. If the results are positive in spite of this bias, then VINTAGE does a good job.

Rather than analyze the vintages of systems in each year, it is easier to examine their "technical age," which makes various years comparable. The "technical age" of a system is defined as 
the difference between the date of observation and a system's vintage. That is,

$$
\text { TECHAGE }=\text { YROBS }- \text { VINTAGE, }
$$

where YROBS is the date of observation' All systems introduced on the same date have the same technical age. The same strengths and weakness that apply to VINTAGE also apply to TECHAGE.

\section{The Distribution of Technical Age.}

Figure 1 presents a summary of the changing technical age of US mainframe computer installations over the entire 16 years (The underlying data are presented in Table A1 in the appendix). A few technical generations dominate the distribution of the technical age over the first years of the sample. The first major technical cohort in the data is associated primarily with the introduction of the IBM system 360 . In the end of 1968 , there were 17580 systems installed whose technical generation is 1965. In each of the next two successive years this technical generation grows to a peak of 27040 systems, which was over $40 \%$ of the systems in use in 1970 . This technical cohort continues to be quite large for many more years, making up more than $20 \%$ of the systems in use up to 1974 . The second major cohort is associated with the IBM system 3 and system 370 (spread primarily through vintages 70-73). By year-end 1974 more than one quarter of the installed systems in use are associated with this new technical generation. The importance of the system 370 and system 3 continues for a few more years. As will be clear below, no other single system introduction influences the measurement results as much as the technical cohorts associated with the system 360 and 370.

Figure 2 presents three different estimates of the average technical age of mainframe

\footnotetext{
7 Since each survey samples the market at the start of the year, YROBS for the first year of the sample will equal 1968.0. YROBS will equal 1983.0 in the final sample year.
} 
computing systems in the United States (Table A2 in the appendix present the raw calculation). Three measures are used because the inferences are sensitive to the measure used. The average technical age of all installations emphasizes popular systems. The average technical age, weighting by the rental value of the installations, emphasizes the newer systems, the bigger systems, and popular systems." The median technical age of the systems installed de-emphasizes any skewness in the distribution.

Figure 2 illustrates the trends. The median has the most unusual pattern. Bocause of the diffusion patterns associated with the system 360 and 370 the median tochnical age jumps discretely year to year. It grows from 1968 until 1973 at a rate of one per year, which reflects the influence of the 360 cohort. As many users bought the system 3 and upgraded their 360 systems to 370 s the influence of the 370 cohort rose. The abrupt decline in the median age of systems between 1973 and 1974 reflects the accumulation of users shifting away from the 360 and to the 370 and system 3 . Both the shifts away from the 360 and to the 370 were necessary to proctuce this abrupt change. It is difficult to make any strong inferences from these movements in the median after 1974. After 1974 the median technical age increases for a few years, stays virtually unchanged for a few years, and then falls markedly in the last couple of years.

The measures of the average technical age of systems stay remarkably close to one another, despite the different weighting used in each case. Not surprisingly, these measures are smoother than the median. They too show a rising average technical age over the early part of the sample. The technical age weighted by value rises 2.3 years from 1968 to 1979 and stays just above six years from 1975 until 1983. The unweighted technical age rises by 3.3 years from 1968 to 1980 and also stays above six years from 1975 onward.

The rise in the technical age over the first half of the sample years is not surprising. The

\footnotetext{
- It may also slightly exaggerate the importance of older systems, as Phister [1979] wams. See appendix for further discussion of these and other potential biases.
} 
computing market had just experienced dramatic growth in the late 1960 s and only moderate growth in the early 1970 s. The average age of systems grew as users held on to their systems and did not retire them. By the mid 1970s, however, users phased out enough of the oldest systems and replaced them with newer systems, resulting in no increasing trend for these averages. The stabilization of the average tochnical age in the later years of the sample is surprising because the continuing existence of some very old systems should bias the measure upward as the market grows older. It seems that the only way to get a stabilization of the average technical age is for buryers to acquire new systems at a fast pace.

Figure 3 verifies the above conjecture. It shows the different quartiles of the vintages of computing capital stock (it also shows the maximum and minimum). The percentage of young systems is growing in the early 1980s and the age of the oldest quartile is falling. Thus, despite the possibility that users could and did hold on to old computing stock, the average age does not change much over the late 1970s and early 1980s. Note that the abrupt change in the maximum tochnical age between 1976 and 1977 reflects one system's retirement and does not reflect any important economic factor.

Is an average technical age of 6 to 7 years a high level or a low level? The obvious benchmark to compare TECHAGE against are several classic diffusion studies. Mansfield's [1968] summary of the diffusion of 12 important innovations in bituminous coal, iron, steel, brewing and railroads, shows enormous variance, as does Griliches' [1957] analysis of the adoption of hybrid seed corn, and David's [1975] analysis of the McCormick Reaper. Most innovations take longer than 10 years to be fully adopted and several take 20 or more years. The comparison is not perfect because these and similar studies analyze the adoption of the first generation of a product innovation (e.g., automobile, radio, television) or process innovation (e.g continuous mining machine, diesel locomotive), not the turnover in technical vintages of a stock of systems in use. Despite this precaution, a technical age of 6 to 7 years seems small in comparison. This measure is biased towards 
a pessimistic answer. New generations of computers must be turning over every few years to produce this result. Very few of the classic studies just mentioned show adoption taking a few years.

A few tentative conclusions emerge. First, the market displays a pattern consistent with the heavy growth of new users in the late 1960s. By the early 1970s this growth slowed and much new technology adoption is being made by experience users. Consistent with this story, estimates of the levels of best practice frontiers are certain to be closer to average practice in the early years of this sample, when first adoptions are made. Similarly, best practice frontiers may provide a deceptive picture of the economic benefits from technical progress in the later years because the gap between best and average practice is likely to be greater for many experienced users. Second, users added new systems at a fast pace in the late 1970 s and early 1980s. This last result is surprising given the rising importance of small substitutes for mainframe computers. Third, there is some indication that new technology comes into use quickly, particular in comparison to previous major innovations. However, this conclusion needs more careful analysis of turnover of computers from different technical generations.

\section{Technical frontiers and the advance of average practice}

The ultimate goal of this section is to measure the speed with which "best practice" diffuses into general economic use. This section corrects for the main deficiency of TECHAGE, that one unit of TECHAGE means the same thing in every year, though each vintage's capabilities differ.

What is meant by "best practice" and "average practice" in a heterogenous product market? Economists typically represent best practice by a "frontier" of models that can provide combinations of product traits at the lowest cost. It follows that "average" practice is a measure of the typical type (and typical cost) of systems in use.

This paper employs traditional hedonic estimates of the best practice frontier in computing. 
Researchers have usually found that the rate of improvement in the performance per dollar of new systems lies somewhere between $15 \%$ and $25 \%$ per year over the whole sample. However, these rates vary year to year and over periods. Unfortunately, most researchers do not estimate changes in the hedonic frontiers over the entire period of interest, from the early 1950 s until 1983 - exceptions are Gordon's [1989] estimates and Triplett's [1989] synthesis of estimates from different researchers.

For estimates of technical frontier, I employ Triplett's [1989] best practice index for computing equipment (Tables 4.13A and 4.14.). This index was Triplett's evaluation and synthesis of the best hedonic research on computer technology. Triplett's indexes start in the mid 1950s and go all the way until 1984. They cover all vintages and all manufacturers in the computing stock. Triplett's index completely covers the industry, which makes it the best choice for this paper.9

Even with an appropriate index, how should it be used to estimate best and average practice? This is particularly important in light of the recent discussion about the existence of multiple hedonic frontiers operating in the market at the same time. ${ }^{10}$ Is it better to assume that all systems for sale are priced on the same frontiet or not? In a putty-putty world, all systems are on the same frontier. Then a system's price and hedonic index are sufficient for comparing different systems' value. If systems are not on the same frontier, what is the appropriate scheme for differentiating between different applications and intensity of use?

The strategy of this paper is to compute a bound on average practice even if system are on

\footnotetext{
'Since Gordon's index and Triplett's index do not shapply differ in the long run, the results are not sensitive to this choice.

${ }^{10}$ Fisher, et al. [1983] argue that the computer market is subject to "disequilibrium." That is, the introduction of new products frequently disrupts expectations, market pricing, and investment patterns. Buyers may lock themselves into investments, but regret the decision as conditions change unexpectedly. In the short run, buryers may be uncertain about the true capabilities of the latest systems and may defer new purchases until better information is available. As a result, the market may never settle into uniform prices for systems with similar characteristics. Hedonic researchers, such as Dulberger [1989] and Oliner [1993a], interpret this to mean that new products and older commercial systems may not lie on the same hedonic frontier. Departures from the frontier may differ with age. Dulberger find evidence in favor of disequilibrium, while Oliner finds a more mixed bag.
} 
different frontiers. Thus, I assign the worse possible frontier to each system. The frontier associated with a system's VINTAGE provides such a lower bound, i.e., the lowest technical frontier for a system is usually realized when a system is first introduced. This is a lower bound because this index will not change with market conditions even though new systems may improve with the introduction of more software or other peripherals. Prices of old systems may also decline in response to new entry driving the technical frontier outward"

Table 1 and Figure 4 show this measure of the computing capital stock More precisely, Table 1 computes the quality adjusted value for each system by dividing the introductory price of the system by a hedonic index for new systems that year. In other words,

$$
E U_{i}=P_{i, r} / H_{v}
$$

where $P_{i, v}$ is the price of system $i$ introduced in year $v$, which is its first year, and $H_{v}$ is the hedonic value of systems of vintage $v .{E U_{i}}_{i}$ represents "efficiency units" or the quality embedded in a system at its introduction, so the number does not change over time. This computation is exactly right if sellers price all new systems on their vintage hedonic surface and the productivity of each model does not dramatically change over time. Otherwise, EU should be interpreted as a lower bound. Table 1 and Figure 4 present the average EU for each year. This equals

$$
\operatorname{AVE}\left(E U_{j}\right)=\left[\Sigma Q_{i} E U_{i}\right]\left[\Sigma Q_{n}\right]
$$

\footnotetext{
"Particularly if the price for a system declines over time or if the technical capabilities for systems improve over the production lifetime of a system. See Oliner [1993a] for evidence that discounting from list prices

follows a general predictable pattem over the commercial life of a system. See Hartman and Teece [1990] for a similar discussion about strategic pricing in the mini-computer industry.
} 
where $Q_{i t}$ is the installed base of model $i$ in year $t$. Median EU is done in an analogous manner. The table ends in 1981 because this is the last year IDC publishes rental price data. A mean and median were used (instead of a total) because these measures minimize biases from arbitrary changes to the definition of a mainframe. The absolute value of the mean is higher than the median bocause in any year the distribution of prices of systems is skewed. That is, the larger systems are more expensive than the smaller systems are cheap.

Consistent with the previous figures, there is no evidence in this table that diffusion is slow. The median and mean start at different levels, but grow at roughly the same rate. The mean grows at 22.6 percent a year, while the modian grows at 23.6 percent a year. The mean shows steady growth after 1970. The decrease from 1969 to 1970 was likely caused by IDCs redefinition of a mainframe, which resulted in the exclusion of many systems from the 1970 census that had been in the 1969 census. The median shows steady growth through out the whole sample, with a few exceptions in the early to mid 1970s. The decline from 1969 to 1970 is an artifact of abrupt changes in the sample of systems. IDC removed several newer systems, mostly minicomputers, from the survey. ${ }^{12}$

The rate of growth shown in Table 1 compares closely with the hedonic index, presented in Table 2. The index declines at 19.8 percent a year from 1958 to 1984 , with the biggest declines coming from 1958 to 1970 . Thus, the decrease in the cost per unit of quality translates into roughly the same rate of growth in the quality of the installed computing capital. Sometimes the rate of growth was even faster.

\section{Diffusion lags}

This section defines and analyzes diffusion lags, which measure how many years average

\footnotetext{
12 Overall, these results do not seem to be a consequence of a change in the typical size of systems in this sample over time. All experiments with changes to the sample of systems yielded similar results.
} 
practice is behind best practice. A diffusion lag is the difference between average practice in one period and its equivalent best practice in a previous time. Diffusion lags are easy to compute with logistic curves in single-product, single-vintage markets. A similar index in a multiple vintage, multiple product market involves a bit more effort.

The paper's measure of the diffusion lag computes the average practice in one year. Then, it fixes that value and searches for the previous year in which best practice frontiers were at this level. The difference in time provides a measure of the "vintage-equivelant" of a given year's average practice. More precisely, let $\mathrm{H}_{4}$ be the best practice value for all systems of vintage $v$, and let AVEPRAC, be the average practice for year $\mathrm{t}$. This paper uses the AVEPRAC in time $\mathrm{t}$ and compares it against previous $\mathrm{H}$, interpolating where necessary. In otherwords, the diffusion lag DIFLAG, is defined by the following procedure:

$$
\begin{aligned}
& \text { If AVEPRAC }(t)=H_{r} \text {, then } \\
& \text { DIFLAG }=t-v
\end{aligned}
$$

This procedure takes advantage of the most data available.

Different definitions of "best practice" and "average practice" provide different insights. As argued above, hedonic measures can represent the technical frontier in time $t$ for all systems introduced in that year. It follows that average practice is the average (or median) of these values over all systems in use.

Table 2 and Figure 5 present the results for 1968 through 1983. The results of this procedure are striking. For the average, diffusion lags grow over the early and middle part of the sample, reaching a peak of over 10 years in 1979, 1980, and 1982. The lags essentially level off in the last five years of the sample. The results show that average practice changes at over 14.4 percent a year 
from 1968 to 1983 , which is just under the 16.4 percent change in best practice during the same years. The diffusion lags lengthen because a number of very old systems are still in the installed base in the late 1970s. Users may or may not use these old systems as intensively as they use new. However, an average does not correct for intensity of use.

One possible correction is shown in Figure 5 and presented in Table 2 under the heading "median practice." It computes the hedonic frontier value of the median system in use. This definition is not as sensitive to the existence of older systems. Of course, this measure will also abruptly change any time the median TECHAGE abruptly changes. The diffusion lag associated with the median practice is markedly different than average practice, as expected. It grows over the early years of the sample, but levels off by 1972. It drops abruptly in 1974, reflecting the abrupt change in the median system, as described in the discussion about the median techage. This drop is in contrast to the average diffusion lag. In addition, the median diffusion lag never exceeds 7 years, which is markedly less than the average diffusion lag. This maximum is reached in 1972, 1973, 1977, 1979, 1980, and 1981. The turnover in the number of young systems is sufficiently fast to prevent the installed base of old systems from mattering as much. I conclude that the modian is a less reasonable measure when there are abrupt changes in the median system, as in the mid 1970s. However, it is a more reasonable measure of long run trends under the assumption that users do not intensively use very old systems. ${ }^{13}$ So it is probably more appropriate for the late 1970 s and early 1980 s.

Several conclusions emerge from Table 2 and Figure 5. First, the overall rate of diffusion of new technology to users embedded in new technology is quite fast, especially considering that all the above measures represent a pessimistic estimate. The average computer user possessed new technology that was improving at roughly the same rate as the best practice frontier, though the level of average

\footnotetext{
${ }^{13}$ This result is also consistent with the industry perception that the "typical" user turns over their system every 4 to 6 years. If the "typical" user makes this purchase 1 to 3 years after the introduction of a product, then a median of roughly 6 to 7 years will result.
} 
practice obviously lagged behind. Second, the gap between the levels of best and average practice grew in the first five years, as one would expect in a relatively new market. Thereafter, the retirement patterns of the older vintages largely determines the measured diffusion gap. Thind, despite the generally positive overall picture, there is considerable variation in the experience of users. A substantial minority continued to possess old equipment, much of it representing generations that were easily 10 years old or older. This observation focuses attention on the need to better understand the relationship between the installed base of old computing equipment, the intensity with which it is used, and users' tendency to make another purchase.

\section{Cosing remarks}

This paper's analysis aimed to prevent any hasty inference about economic welfare based solely on estimates of growth in the computing technical frontier. What matters for economic welfare is what technologies users employ, not only what is available or what was recently bought. In terms of this motivation, the results were quite positive. Average practice generally lagged best practice by a maximum of 6 to 7 years and was often shorter. While this answer is somewhat sensitive to assumptions about the intensity of use of old systems, it is biased towards a pessimistic answer. A maximum of 6 to 7 years is hardly slow, especially in comparison to the diffusion of other important innovations.

The analysis highlighted several important features of the diffusion of computing. A few vintages and computer system models greatly influence the results in some years. It follows that any measurement of diffusion will be sensitive to the valuation placed on popular systems, particularly the IBM system 360 and the IBM system 370 . This is a disturbing conclusion, given the different hedonic estimates for these systems (Gordon [1989], Dulberger [1989], Oliner [1993a]).

Second, the analysis found a general correlation between advances in technical frontiers and 
advances in average practice, but also found much variation around the trend. A large number of users continued to hold onto old equipment and did not turnover technical generations quickly. By impliction, a complete description of the advance of average practice requires a complete survey of the experience of new and popular systems, and also a survey of the use of old vintages. Thus, at best, hedonic frontiers alone are a weak approximation of the general economic benefits from technical advance in the short nu. These observations highlight the need to better understand the relationship between the elasticity of demand for computing the intensity of use of old technical vintages, and the adoption of new technology (e.g., See Bresnahan and Greenstein [1993]). Further research on the intensity of use of old equipment and its retirement patterns (e.g., Oliner [1993a], [1993b]) can partially address this gap in knowledge.

The paper's results have another important implication. Economists have been puzzled by the absence of any of the expected productivity improvements that should follow technical advances in computers. One set of possible hypotheses emphasize that average practice lagged far behind best practice. This paper provides a quantitative test of the simplist slow-diffusion mechanism, that new technology embedded in hardware diffused slowly. The analysis rejects this mechanism because average practice advanced at a rate comparable to best practice and the diffusion lag associated with new technology embodied in mainframe hardware was typically short. Thus, to remain viable, the slow-diffusion hypothesis must focus on the slow development of software, human learning and appropriate organization forms, as suggested in David [1989], if it is to survive as a viable explanation for the productivity puzzle. ${ }^{14}$

This paper's experiment ends at an interesting turning point in the mainframe computer

\footnotetext{
${ }^{14}$ These is not likely any supporting evidence in the diffusion of products complementary to hardware, such as software or peripheral components. Recent hedonic research shows a rapid rise in the technical frontier for many different peripherals (Cole et al [1986], Oliner [1993b]). Since the sale of these peripherals positively correlates with sale of processors, there is likely to be little difference in the diffusion lag for peripheral technologies in the United States.
} 
industry. Super minicomputers had already begun cutting into the mainframe market share by 1983 and personal computers became much more ubiquitous within businesses after 1983 (Bresnahan and Greenstein [1993]). One might expect the retirement patterns and acquisition patterns to change as a result. Further research may be able to identify whether the diffusion lags increased or decreased after 1983.

Further work could construct estimates of the demand for computing capabilities. Demand estimates will say something about the degree of change in the surplus of users due to tochnical improvement. This is the spirit of Flamm's [1987a] estimate of the benefits from improvements in computer systems, Bresnahan's [1987] research on the use of computers in the financial services sector, and Trajtenberg's [1989,1990] estimates of the welfare gain from the adoption of CT scanners. Since the data in this paper includes data on quantity and prices, it is possible to work in this direction. Greenstein [1993b] contains such research 
Table 1

Medtan and Average Efficiency Onits 1968-1981

\begin{tabular}{|l|r|r|}
\hline Year & \multicolumn{1}{c}{ Mean } & \multicolumn{1}{c|}{ Modian } \\
\hline 1968 & 22.28 & 5.00 \\
1969 & 22.33 & 7.04 \\
1970 & 19.33 & 10.55 \\
1971 & 25.41 & 10.55 \\
1972 & 35.90 & 10.55 \\
1973 & 45.10 & 11.41 \\
1974 & 54.99 & 11.41 \\
1975 & 65.19 & 11.41 \\
1976 & 71.02 & 13.70 \\
1977 & 92.65 & 28.92 \\
1978 & 135.16 & 48.40 \\
1979 & 209.45 & 63.52 \\
1980 & 323.40 & 70.04 \\
1981 & 529.00 & 136.61 \\
& & \\
\hline
\end{tabular}


Table 2

Average vergus Best Practice 1968-1983

\begin{tabular}{|c|c|c|c|c|c|}
\hline Year & $\begin{array}{l}\text { Fedonic } \\
\text { Beat } \\
\text { Practice }\end{array}$ & $\begin{array}{l}\text { Average } \\
\text { Practice }\end{array}$ & $\begin{array}{l}\text { Average } \\
\text { Diffusion } \\
\text { Lag }\end{array}$ & $\begin{array}{l}\text { Median } \\
\text { Practice }\end{array}$ & $\begin{array}{l}\text { Median } \\
\text { Diffusion } \\
\text { Lag }\end{array}$ \\
\hline $\begin{array}{l}1957 \\
1958 \\
1959 \\
1960 \\
1961 \\
1962 \\
1963 \\
1964 \\
1965 \\
1966 \\
1967 \\
1968 \\
1969 \\
1970 \\
1971 \\
1972 \\
1973 \\
1974 \\
1975 \\
1976 \\
1977 \\
1978 \\
1979 \\
1980 \\
1981 \\
1982 \\
1983\end{array}$ & $\begin{array}{r}3640.9 \\
2895.5 \\
2422.7 \\
1863.6 \\
1377.3 \\
927.3 \\
700.0 \\
568.2 \\
454.6 \\
286.4 \\
231.8 \\
190.9 \\
172.7 \\
159.1 \\
122.7 \\
100.0 \\
98.6 \\
80.3 \\
73.2 \\
65.7 \\
51.4 \\
34.5 \\
29.6 \\
23.9 \\
21.8 \\
20.4 \\
16.3\end{array}$ & $\begin{array}{r}794.2 \\
671.7 \\
556.3 \\
503.6 \\
422.8 \\
380.9 \\
313.0 \\
274.5 \\
229.4 \\
224.2 \\
199.1 \\
186.4 \\
168.7 \\
136.6 \\
116.0 \\
91.4\end{array}$ & $\begin{array}{l}5.4 \\
5.8 \\
5.8 \\
6.4 \\
6.8 \\
7.6 \\
8.2 \\
8.8 \\
8.9 \\
9.8 \\
10.2 \\
10.7 \\
10.7 \\
10.3 \\
10.7 \\
9.6\end{array}$ & $\begin{array}{r}568.2 \\
454.6 \\
454.6 \\
454.6 \\
454.6 \\
286.4 \\
159.1 \\
159.1 \\
159.1 \\
159.1 \\
100.0 \\
100.0 \\
98.6 \\
80.3 \\
65.7 \\
34.6\end{array}$ & $\begin{array}{l}4 \\
4 \\
5 \\
6 \\
7 \\
7 \\
4 \\
5 \\
6 \\
7 \\
6 \\
7 \\
7 \\
7 \\
6 \\
5\end{array}$ \\
\hline
\end{tabular}




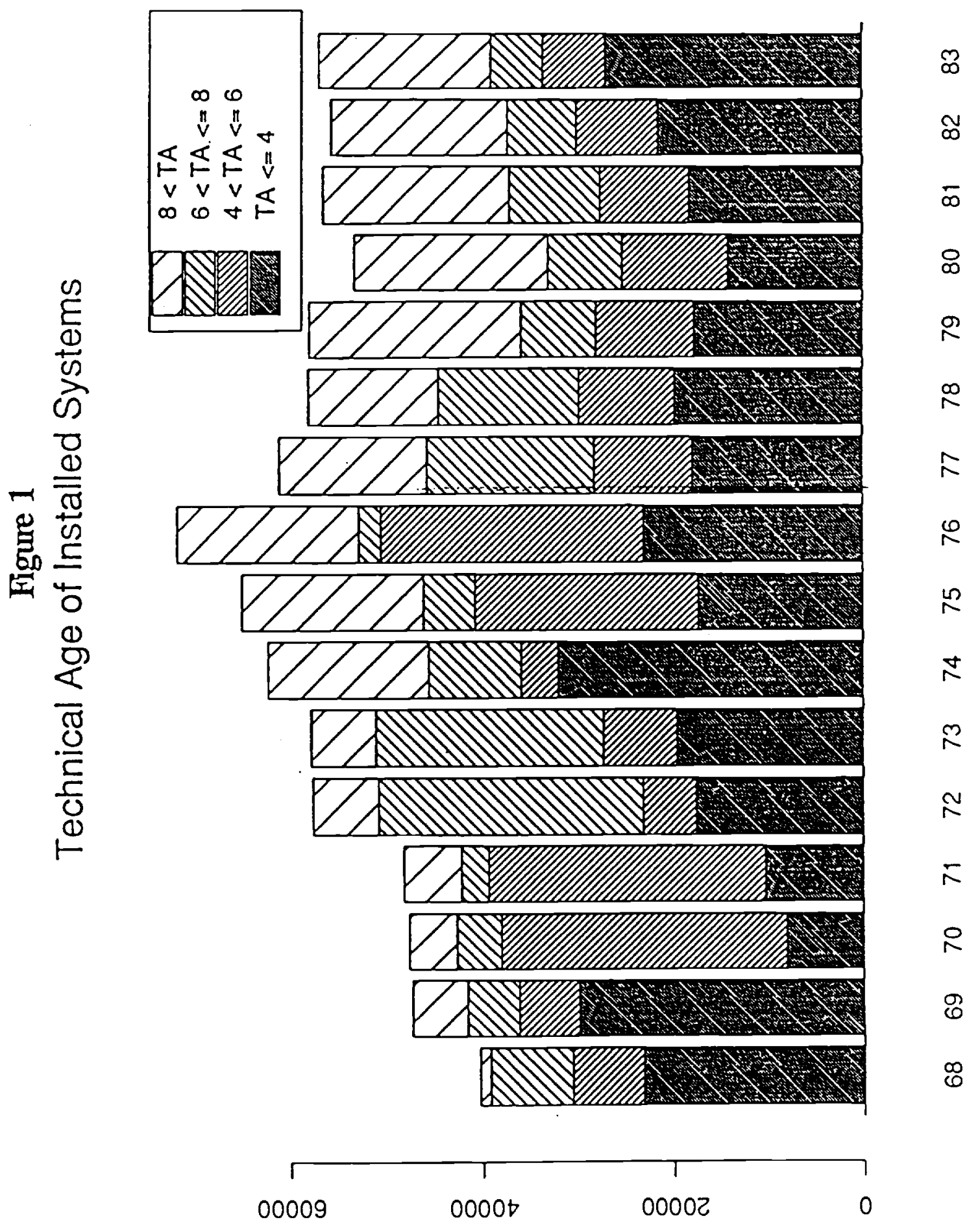




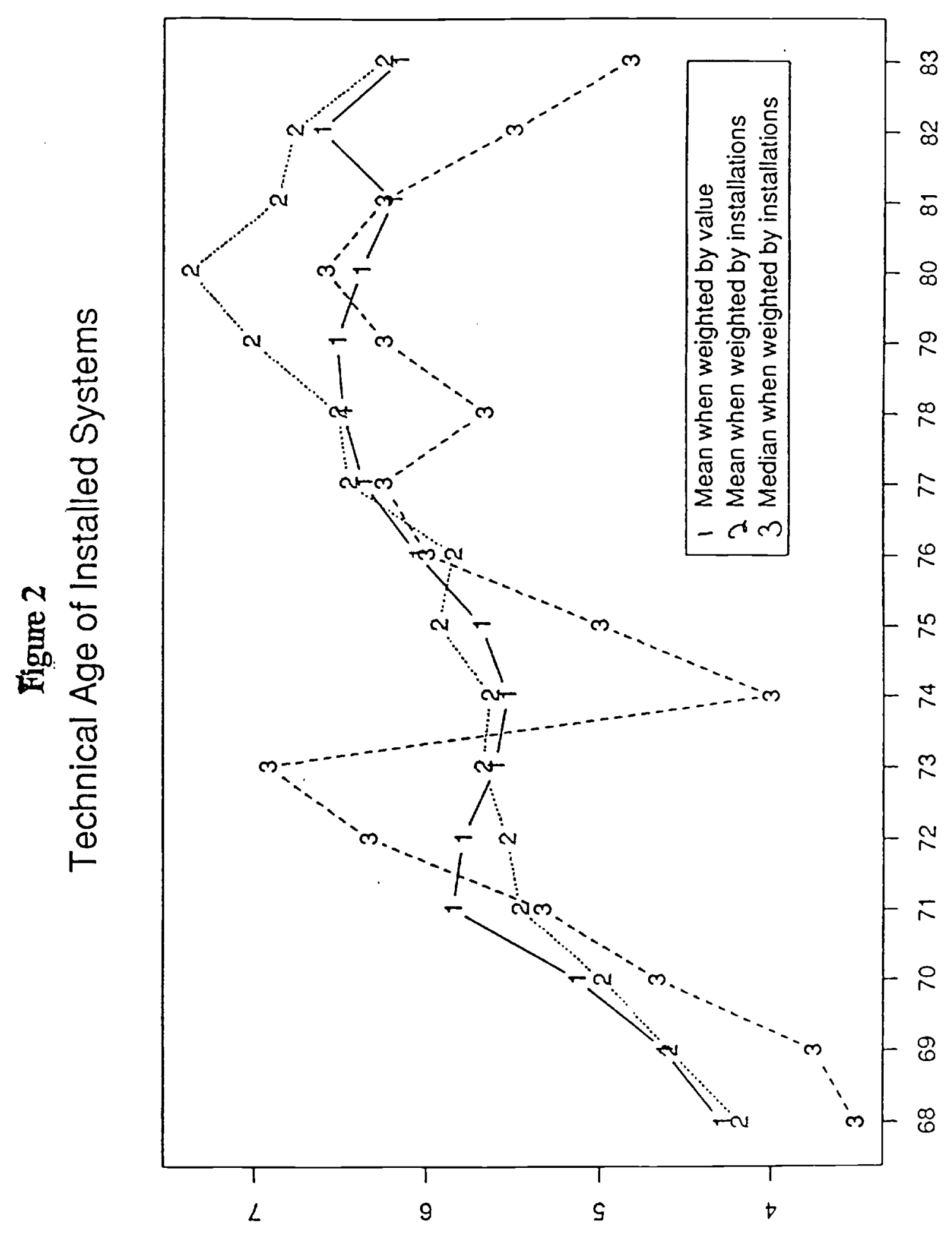




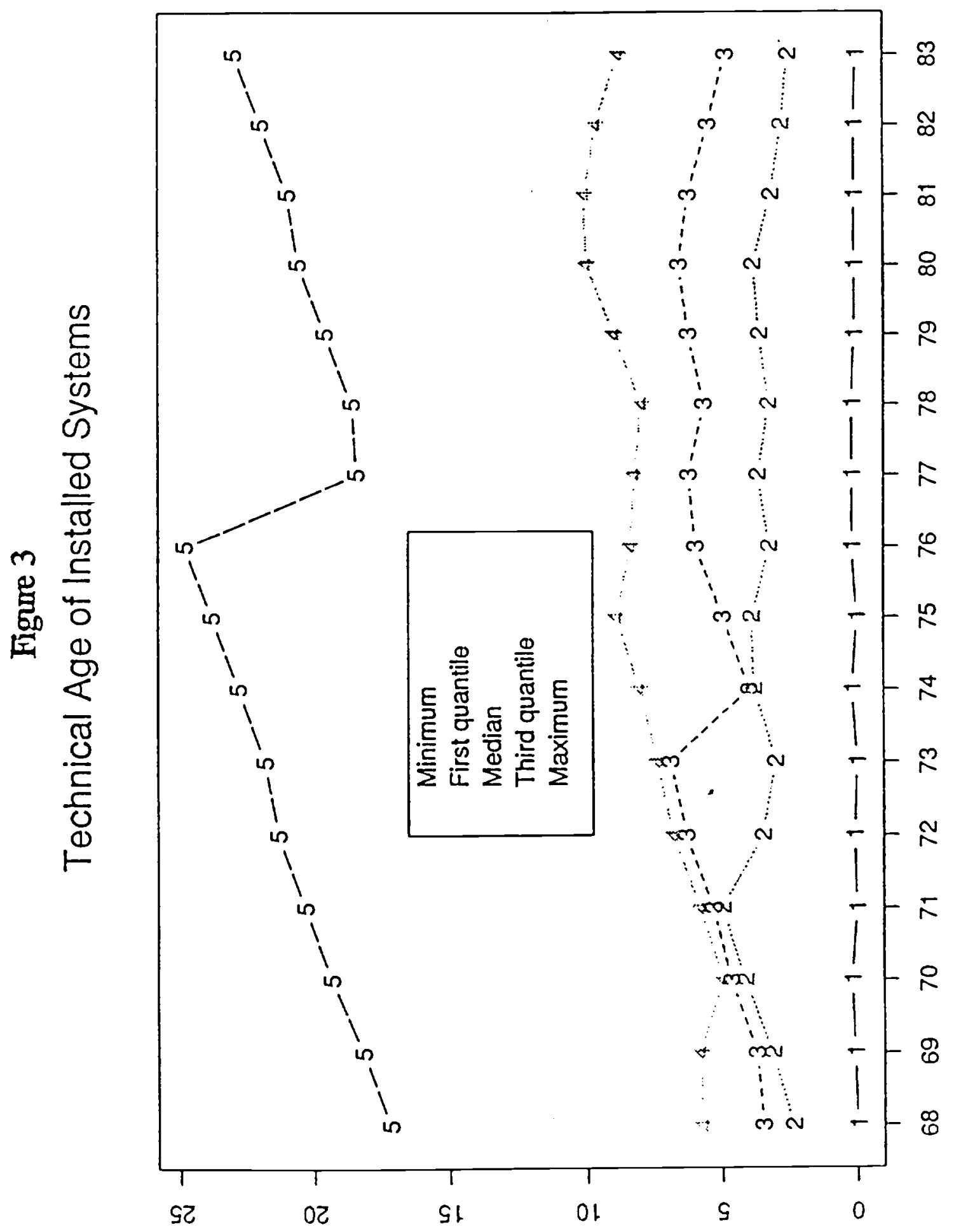




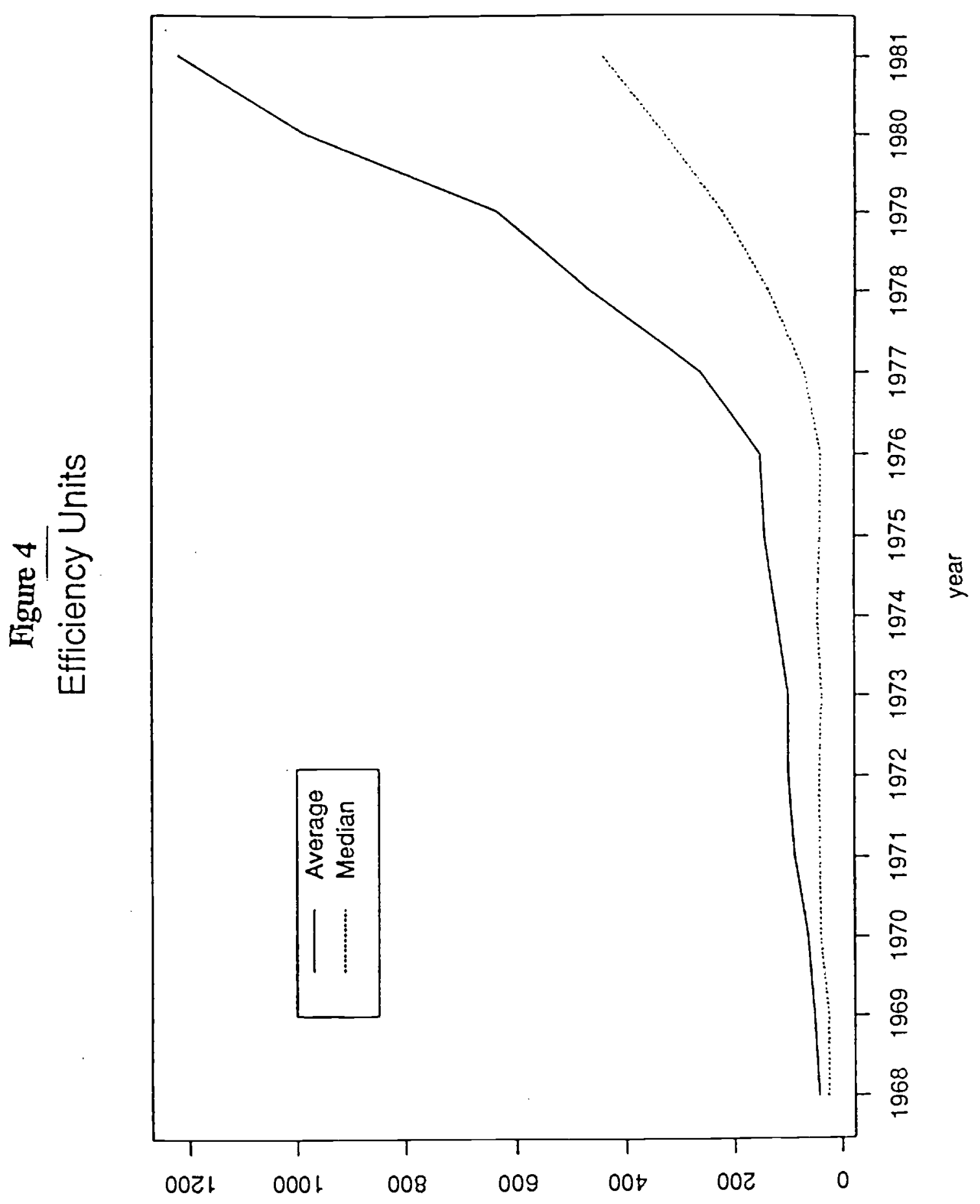




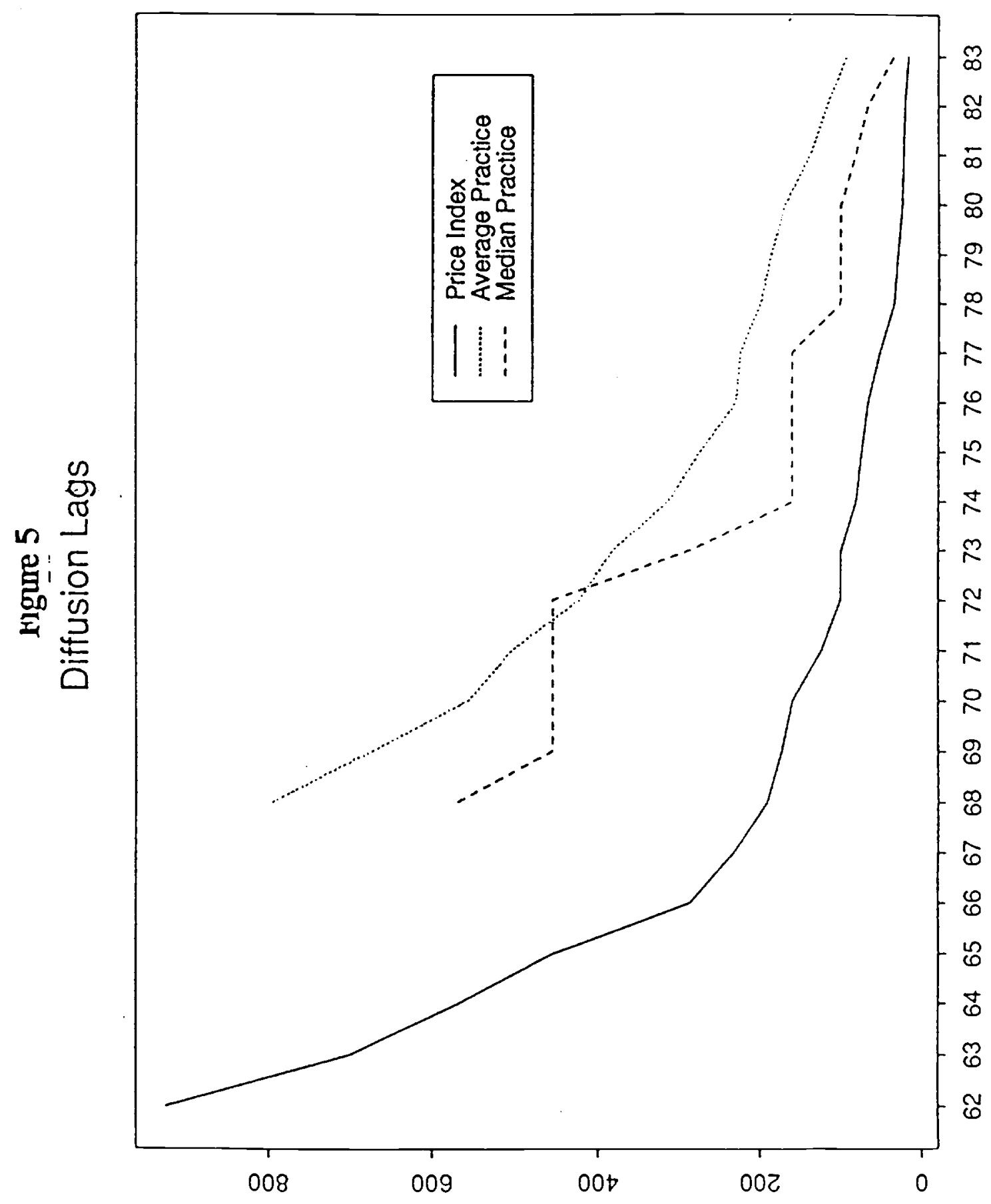




\section{References}

Berndt, Emst [1991], The Practice of Econometrics: Classic and Contemporary, Reading, MA: Addison-Wesley.

Berndt, Ernst, and Zvi Griliches [1990], "Price Indexes for Microcomputers: An Exploratory Study," NBER working paper \#8878, Cambridge, MA.

Berndt, E. R, M. H. Showalter, and J. M. Woolridge [1991], "On the sensitivity of hedonic price indexes for computers to the choice of fucntional form," Mimeo.

Berndt, Emst, R and Catherine J. Morrison [1991], "Assessing the Productivity of Information Technology Equipment in U.S. Manufacturing Industries," NBER Working Paper 3582, Cambridge, MA, January 1991.

Berndt, Emst, R, Catherine J. Morrison, and Larry Rosenblum [1992], "High-Tech Capital formation and labor Composition in U.S. Manufacturing Industries: An Exploratory Analysis," NBER Working Paper 4010, Cambridge MA, March 1992.

Bresnahan, Timothy, F. [1987], "Measuring the Spillover from Technical Advance: Mainframe Computer in Financial Services," American Economic Review, March.

Bresnahan, Timothy, F. and Shane M Greenstein [1993], "The Competitive Crash in Large Scale Computing," mimeo, University of Illinois.

Brock, Gerald W. [1975], U.S. Computer Industry: A Study in Market Power, Cambridge Mass: Ballinger Publishing Co. 1975

CBEMA [1992], Information Technology Industry Databook, 1992, Washington, D.C.

Cole Rosanne, Chen, Y.C., Barquin-Stolleman, Joan A, Dulberger, Ellen, Helvacian, Hurhan, and Hodge, James H. [1986], "Quality-Adjusted Price Indexes for Computer Processors and Selected Peripheral Equipment," Survey of Current Business, 66(January), pp. 41-50.

David, Paul A. [1975], "The Mechanization of Reaping in the Ante-Bellum Midwest," in Technical Choice, Innovation, and Economic Growth: Essays on American and British Experience in the Nineteenth Centry, Cambridge University Press, New York, NY.

David, Paul A. [1989], "The Computer and the Dynamo: the Modern Productivity Paradox in a Not-Too-Distant Mirror," CEPR Working Paper no. 172, Stanford University, July.

Dulberger, Ellen R [1989], "The application of a Hedonic Model to Quality-Adjusted Price Index for Computer Processors," in Technology and Capital Formation, Edited by Dale W. Jorgenson and Ralph Landau, MIT Press. 
Fisher, Franklin M and MoGowan, John J., and Greenwood, Joen E. [1983], Eolded. Spindled, and Mutilated: Economic Analysis and U.S. vs. IBM MT Press, Cambridge Mass..

Flamm, Kenneth [1987a], Targeting the Computer: Government Support and International Competition, Washington D.C.: The Brookings Institute.

Flamm, Kenneth [1987b], Creating the Computer Government, Industry, and High Technology Washington D.C.: The Brookings Institute.

Gordon, Robert J. [1989], "The Postwar Evolution of Computer Prices," in Technology and Capital Formation, Edited by Dale W. Jorgenson and Ralph Landau, MIT Press.

Greenstein, Shane [1993a], "The Diffusion of Multiple Vintages in a Differentiated Product Market: Best and Average Practice in Mainframe Computers: 1968-1983," mimeo, University of Illinois.

Greenstein, Shane [1993b], "From Superminis to Super-computers: Estimating the Benefits from Improvements in Computing," Mimeo, University of Illinois, November.

Griliches, Zvi [1957, "Hybrid Com: An Exploration in the Economics of Technological Change," Econometrica, 25, pp. 501-22.

Hartman, Raymond S. and Teece, David J. [1990], "Product Emulation Strategies in the Presence of Reputation Effects and Network Extemalities: Some evidence form the Minicomputer Industry," Economics of Innovation and New Technology.

Michels, Robert [1979], "Hedonic Prices and the Structure of the Digital Computer Industry," Joumal of Industrial Economics.

Mansfield, Edwin [1968], Industrial Research and Technological Innovation New York: Norton.

Oliner, Steve [1993a], "Constant Quality Price Changes, Depreciation, and Retirement of Mainframe Computers," in Price Measurement and Their Uses, edited by Murray F. Foss, Marilyn E. Manser, and Allan H. Young University of Chicago Press, Chicago, IL.

Oliner, Steve [1993b], "Estimates of Depreciation and Retirement for Computer Peripheral Equipment," Mimeo, Board of Governers of the Federal Reserve System, Division of Research and Statistics.

Phister, Montgomery, Jr. [1979], Data Processing Technology and Economics, Digital Press, Santa Monica.

Trajtenberg, Manuel [1990], Economic Analysis of Product Innovation The Case of CT 
Scanners, Harvard University Press, Cambridge MA.

Trajtenberg Manuel [1989], "The Welfare Analysis of Product Innovations, with an Application to Computed Tomography Scanners," Joumal of Political Economy, 97, 2, April.

Triplett, Jack E. [1989], "Price and Technological Change in A Capital Good: A Survey of Research on Computers," in Technology and Capital Formation, Edited by Dale W. Jorgenson and Ralph Landau, MT Press. 


\section{Appendix}

\section{Al. Data documentation}

These data on computer prices, quantities, and vintages come from the archives of the Charles Babbage Institute at the University of Minnesota, which contains a collection of industry "censuses" from International Data Corporation's (IDC) EDP Industry Reports (EDP/IR). This paper also makes use of a set of EDP Industry Reports contained at the Library for the Graduate School of Business at Stanford University. Patrick McGovern began compiling this census in 1962 in Computers and Automation magazine. It continued in modified form under IDC auspices from the mid 1960s onward. IDC annually surveyed most mainframe users and suppliers in the country and estimated the number of installations of each type of computer system. In addition, until 1981 IDC estimated the monthly rental at which an average type of the system leased. After 1981 they estimated an average purchase price for the system.

The IDC data on the installed base of each model is the right magnitude, though not precise, especially in capturing yearly changes. IDCs own literature wams against the hazards of inferring net sales from changes in the data on installed base. The problem is that they update their figures for two reasons: (1) Real changes in the holdings of users; (2) changes in IDCs information about (proprietary) sales activity, both in the present and in the past. Patrick McGovern recalls (in a private communication) that most suppliers except IBM cooperated with IDC, which is why IDC had to undertake a major revision of the data pertaining to IBM's systems (Phister [1979] contains a complete set of these revisions).

Phister [1979] clearly believes that IDCs estimates are the best among the available alternatives. He states on pg. 250 "It is my opinion that IDCs staff, files, and data sources make that organization's published statistics the best available." Nevertheless, he wams about several potential problems that could influence calculations using these data. For example, due to occasional revisions of previous EDP/IR reports, Phister is not convinced that IDCs estimates of the size of installed base are precise. However, many of his uses of these data indicate that he believes IDC got the general order of magnitude correct.

Dulberger also questions the accuracy of IDCs estimates of installed base, while conceding that they are the best publicly available. One especially difficult problem is that IDC may underestimate the number of users who upgrade their systems (Dulberger, private communication). However, she relies less directly on IDCs numbers. She used them only to determine the size of her data sample of systems for sale in a given year. For 
each year's sample she included processors associated with systems whose installed base was still growing since these systems are likely to still be experiencing positive sales.

Given these concerns, I also subjected these data to some internal consistency checks, which they readily met. The history of each new system was examined. Did the development of its installed base follow a reasonable pattern of growth, i.e., several years of growth followed by several years of decline? The absence of such a pattem would bring into question the plausibility of the data

Similar issues influence the use of IDCs rental price data IDC estimated the price of a typical system configuration. Phister believes that the prices for obsolete systems are too high, since IDC would use the last offered price for a system in the absence of any recent transaction. Nonetheless, Phister uses these prices for estimates of the value of installed base. He believes that the bias in old prices influences only a few of the systems in the United States. Flamm reaches a similar conclusion before using Phister's estimates for a few calculations. In addition, using these prices is not withourt precedent in the hedonic literature. The prices for new systems used by Gordon (as well as many others) are very similar to those used here. Gordon's prices for his sample after 1977 were taken from Computerworld, which is published by IDC.

These researcher's experiences show that IDCs estimates are probably the right order of magnitude, but also subject to measurement error. These observations warrant a cautious research strategy. No strong conclusions should rely exclusively on one data point. Strong inferences will arise only from procedures in which cumulative measurement errors wash ort. 


\section{A2. The Technical VINTAGE of Impontant Mainframe Computer Systems}

\section{VINTAGE $=50$ \\ UNI1103/5 \\ VINTAGE -51 \\ UNIIII \\ VINTAGE $=54$ \\ BUR205 \\ 1BM650 \\ VINTAGE $=55$ \\ IBM704 \\ IBM705 \\ VINTAGE-57 \\ IBMB05 \\ UNIIII \\ VINTAGE $=58$ \\ BUR220 \\ IBM709 \\ PHI210211 \\ UNISS80190 \\ VINTAGE $=59$ \\ IBM7090 \\ UNI501}

VINTAGE $=60$

CDC1604/A/B, GEL210, HONH800, IBM1401, IBM1620, IBM7070/74, IBM7090/94, NCR304, UNI30I, UNILARC

VINTAGE $=61$

BUR200, CDCG-20, GEN225/255, HONH400, IBM1410, IBM7030, IBM7080, NCR310, NCR390, RCA301, UNI491/492,

VINTAGE $=62$

IBM7094, NCR315, RCA605, UNIII UNI1107,

VINTAGE $=63$

BURB55/5700, CDC3600, GEL215, IBMI440, IBM1460, IBM7010, IBM7040/44, PHI1000, PHI212, UNI418UI, UNI1004, UNI1050,

VINTAGE $=64$

BURB100S, CDC31/3150, CDC3200, CDC3400, CDC6600, DECPDP6, GEL205, GEJ 235/265, GEL415/420, GELA25/430, HON200, HON1400, HON1800, HONGAMMA10, IBM1401G, IBM7094-II, UNI3301, XER9300,

\section{VINTAGE $=65$}

BURB300S, CDC3300, CDC3800, GEI 235/265, GEL435/440, GEL625, GEL635, IBMB60/20, IBMB60/30, IBMB60/40, IBMB60/50, IBMB60/65, NCR315RMC, NCR500, RCAS70/15, RCAS70/25, UN11108,

\section{VINTAGE -66}


CDC6400, GEL55, GEL115, GEL645, HONH120, HONH1200, HONH2200, LBMB60/44, IBMB60/67, IBMB60/75, IBMI 130, RCAS70/55, UNI494, UNI1005, XERSIGMA7, XER940

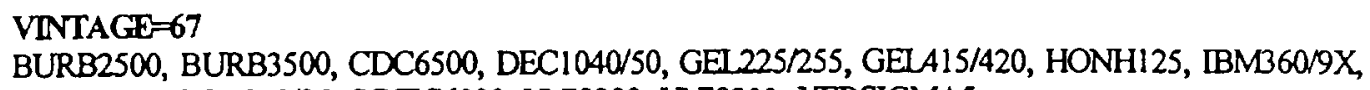


HONH68/DPS, IBMB031, IBMB032, IBMB033U,A,M MAGM80/4, NASAS3, NASAS77031, NASAS/6, NCR8370, NCR8430, NCR8580, UNI90/40, UN11100/83, UNI1100/84,

VINTAGE-79

AMD470V/8, CAX1638/40, CDCCYB170-720, CDCCYB170-730, CDCCYB170-750, CDCCYB170-760, DEC2060, HONH64/300, HONH66/440/520, HONCOMXXR, IBM4331-1, IBM4341-1, MAGM80/3, NASAS77020/30, NCR8270, NCR8410, NCR8455, NCR8555, NCR8565, NCR8575, NCR8585, ,

\section{VINTAGE $=80$}

BURB1905, BURB1955/85, BURB2900, BURB6900, CAX1641, CDCOMEGA480-3, CDCCYBER203 , CDCCYB170-740, CRAY1S HONDPS8/20, HONDPS8/44, HONDPS8/52, HONDPS870, HONDPS4, IBMSYS38/3, IBMSYS38/5, IBM4331-2, IBMB033N, IPL4436, IPL4443, MAGM80/31, MAGM80/32, NASAS 3000, NASAS/5000, NASAS77000, NASAS19000, UNISYS80-3-4 UNI1 100/60,

\section{VINTAGE $=81$}

AMD470V/7C, BURB3955, BURB5930, CAX1636, CDCCYBER205, HONDPS8/62, HONDPS7, IBMSYS38/4, IBM4341-2, IBMB033S, IBMB081D, IPL4446, MAGM80/30, MAGM80/30E, MAGM80/42, MAGM80/43, NCR8650,

\section{VINTAGE $=82$}

AMD580/5860, BURB5920, BURB6925, CAX1651, CDCCYBER855, CDCCYB170-825, CDCCYB170-835, CDCCYB170-855 , CDCCYB170-875, DENHEP IBMSYS387, IBM4321, IBM4331-11, IBM4341-10, IBM4341-11, IBMB081G, IBMB081K, IPL4445, MAGM80/20, MAGM80/41, NASAS/6600, NASAS 9040 , NASAS/9050, NASAS/9060, ,NASAS/9070, NASAS/9080, NCR8535II, NCR8545I, NCR8555II, NCR8565II, NCR8670, NCR8575II, NCR8585II, NCR8595II, UNISYS80-5-6

\section{VINTAGE= 83}

AMD580/5850 , AMD680/5870 , AMD580/5880, BURB2925, BURB4955, BURB7900FHK, CAX1636-10, CAX1641-11, CAX1651-11, CDCCYB170-865, CDCCYB170-875D, CRAYXMP22, CRAYXMP24, CRAYM HONDPS88/81 , HONDPS88/82, HONDPS837, HONDPS849, IBMSYS38/8, IBM4341-9, IBM4341-12, IBMB083E, IBMB083B, IBMB083J, IPL4460, IPL4480, NCR8635, NCR8645, NCR8655, NCR8665, NCR8675, NCR8685, NCR8695, UNISYS80-8, 
Table Al

The Technical Age of the Installed Base of Canuters

\section{8-1983}

\begin{tabular}{|c|rrrrrrrr||}
\hline Age & 68 & 69 & 70 & 71 & 72 & 73 & 74 & 75 \\
\hline$<1$ & 549 & 338 & 493 & 476 & 1500 & 1353 & 1509 & 2121 \\
$1-2$ & 1651 & 1182 & 2920 & 3138 & 4073 & 5211 & 3539 & 3900 \\
$2-3$ & 17580 & 2653 & 2698 & 3839 & 7119 & 3315 & 6392 & 5433 \\
$3-4$ & 3491 & 25824 & 719 & 2935 & 4965 & 9702 & 5137 & 5964 \\
$4-5$ & 4168 & 3031 & 27040 & 730 & 3605 & 3816 & 16596 & 5204 \\
$5-6$ & 3223 & 3157 & 4152 & 28240 & 759 & 3773 & 2691 & 17987 \\
$6-7$ & 1882 & 2946 & 1477 & 910 & 27791 & 5942 & 3953 & 1974 \\
$7-8$ & 6642 & 2424 & 3195 & 1329 & 856 & 17923 & 4501 & 3381 \\
$8-9$ & 220 & 4784 & 1087 & 2475 & 1251 & 1295 & 12244 & 4021 \\
$9-10$ & 184 & 203 & 3259 & 908 & 2277 & 1889 & 1063 & 10229 \\
$10-11$ & 76 & 142 & 360 & 2730 & 712 & 480 & 1611 & 912 \\
$11-12$ & 124 & 58 & 131 & 309 & 2401 & 859 & 375 & 1387 \\
$>12$ & 503 & 532 & 90 & 141 & 303 & 2232 & 2636 & 2523 \\
\hline Total & 40293 & 47274 & 47621 & 48160 & 57612 & 57790 & 62247 & 65036 \\
\hline
\end{tabular}

\begin{tabular}{|r|rrrrrrrr|}
\hline & 76 & 77 & 78 & 79 & 80 & 81 & 82 & 83 \\
\hline$<1$ & 6888 & 2507 & 1028 & 700 & 947 & 3483 & 873 & 5940 \\
$1-2$ & 5152 & 4512 & 6870 & 2802 & 2157 & 6937 & 6556 & 5409 \\
$2-3$ & 5186 & 4949 & 6355 & 7923 & 3994 & 3499 & 10851 & 6190 \\
$3-4$ & 5927 & 5882 & 5480 & 6312 & 7129 & 4380 & 3285 & 9563 \\
$4-5$ & 4845 & 6291 & 4424 & 5765 & 4779 & 5839 & 4406 & 3137 \\
$5-6$ & 5824 & 4093 & 5712 & 4079 & 6202 & 3486 & 4147 & 3392 \\
$6-7$ & 17632 & 4276 & 3547 & 5218 & 3801 & 5832 & 2378 & 3094 \\
$7-8$ & 1338 & 13123 & 3078 & 3035 & 4056 & 3349 & 4711 & 2331 \\
$8-9$ & 3169 & 742 & 8810 & 2713 & 2419 & 3082 & 2800 & 3902 \\
$9-10$ & 3360 & 2136 & 547 & 7624 & 2280 & 2038 & 2105 & 2250 \\
$10-11$ & 8671 & 2703 & 1680 & 502 & 6065 & 1984 & 1511 & 1340 \\
$11-12$ & 813 & 6469 & 2186 & 1569 & 401 & 4925 & 1601 & 1054 \\
$>12$ & 3089 & 3417 & 8306 & 9718 & 9013 & 7681 & 10418 & 9358 \\
\hline Total & 71894 & 61100 & 58023 & 57960 & 53243 & 56515 & 55642 & 56960 \\
\hline
\end{tabular}


Table A2

Technical age of a typical system 1968-1983

\begin{tabular}{|c|c|c|c|}
\hline Year & $\begin{array}{l}\text { Average } \\
\text { waighted } \\
\text { by value }\end{array}$ & $\begin{array}{l}\text { Avarage } \\
\text { weighted } \\
\text { by Ingtall }\end{array}$ & Median \\
\hline 1968 & 4.29 & 4.18 & 3.50 \\
1969 & 4.62 & 4.60 & 3.75 \\
1970 & 5.13 & 4.99 & 4.66 \\
1971 & 5.85 & 5.46 & 5.33 \\
1972 & 5.79 & 5.53 & 6.33 \\
1973 & 5.60 & 5.67 & 6.91 \\
1974 & 5.53 & 5.63 & 4.00 \\
1975 & 5.69 & 5.93 & 5.00 \\
1976 & 6.05 & 5.85 & 6.00 \\
1977 & 6.37 & 6.45 & 6.25 \\
1978 & 6.48 & 6.51 & 5.66 \\
1979 & 6.52 & 7.02 & 6.25 \\
1980 & 6.38 & 7.38 & 6.58 \\
1981 & 6.20 & 6.87 & 6.25 \\
1982 & 6.61 & 6.77 & 5.50 \\
1983 & 6.16 & 6.25 & 4.83 \\
& & & \\
\hline
\end{tabular}

